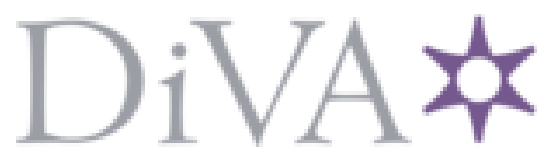

http://www.diva-portal.org

This is the published version of a paper published in Journal of Health Science.

Citation for the original published paper (version of record):

Aléx, J., Lundin, H., Joansson, C., Saveman, B-I. (2017)

Preparedness of Swedish EMS Personnel for Major Incidents in Underground Mines

Journal of Health Science, 5: 239-243

https://doi.org/10.17265/2328-7136/2017.05.004

Access to the published version may require subscription.

N.B. When citing this work, cite the original published paper.

This work is licensed under a Creative Commons Attribution-NonCommercial 4.0

International License https://creativecommons.org/licenses/by-nc/4.o/

Permanent link to this version:

http://urn.kb.se/resolve?urn=urn:nbn:se:umu:diva-151321 


\title{
Preparedness of Swedish EMS Personnel for Major Incidents in Underground Mines
}

\author{
Aléx Jonas, Lundin Helena, Joansson Charlotta and Saveman Britt-Inger \\ Department of Nursing, Umeå University, Umeå SE-901 87, Sweden
}

\begin{abstract}
The purpose of this study was to survey the EMS (emergency medical services) personnel preparedness for major incidents in the underground mining industry in Sweden. Every year, a high number of incidents, workplace accidents and fires are reported from the Swedish mining industry. Taking care of patients located in an underground mine represents a challenge to EMS personnel. Today, knowledge about EMS personnel preparedness for major incidents in the mining industry is limited. The study design was a cross-sectional survey. The questionnaires were distributed to EMS personnel working in ambulance stations geographically located near an underground mine. Thirteen ambulance stations were included and 137 of 258 personnel answered. Demographic data were analyzed using descriptive statistics. Differences among groups were analyzed with the Chi-Squared test, continuity correction and t-test. Results showed about half of the participants reported that they do not feel prepared to work in a major incident in an underground mine. The majority wished to receive educational training to enhance their preparedness. The most commonly requested type of education was practical drills on the scene, in an underground mine. The reported preparedness was significantly higher among the participants who had received some kind of education, or had authentic experience of a mission in an underground mine than those who did not. This study reveals shortcomings in the preparedness of EMS personnel. The perceived low preparedness of EMS personnel may affect their ability to work in a major incident in the mining industry. Study findings may be used in planning the future education, including practical drills, of EMS personnel.
\end{abstract}

Key words: Ambulance personnel, EMS, major incident, mining industry, preparedness, underground mine.

\section{Background}

Underground mining is associated with obvious risks which may lead to mass-casualty incidents. A literature review show that a majority of the reports were descriptive regarding injury-creating technical and environmental factors and a lack of focus on rescue and medical aspects [1]. There is a need for evaluation of the preparedness to handle underground mining incidents among (EMS) emergency medical services staff during rescue operations.

In many parts of the world, underground mining operations are a very risky situation for employees [2-4]. Each year thousands die in incidents in coal, stone and ore mines [5].

The mining industries in the in the western world are not spared from major incidents and disasters. On New Zealand's West Coast, 29 miners were killed

Corresponding author: Aléx Jonas, Ph.D., research field: prehospital emergency care. after an explosion in the Pike River Mine, in 2010 [6]. An American study explains that 11,606 workers died in disasters in underground mines between the years 1900-2006. During a five-month period of 200619 miners died in three different mining disasters, where fires and explosions were the causes [7]. Muzaffar et al. [8] investigated the statistics of loss events in the American mining industry between the years 1998-2007. The results showed that more entrepreneurs than mining workers were killed by harmful incidents, and that the most common causes involve transportation, machinery, electricity and falling objects and slipping or cases.

Despite ongoing safety efforts by the Swedish mining industry, different types of harmful events occur annually. To evacuate and treat affected and/or injured patients who are in an underground mine is a challenge for all rescue organizations and requires good planning for such events. Today's scientific 
knowledge of EMS personnel preparedness for major incidents in the mining industry is very limited.

Major incidents are relatively rare, but when they do occur, demands are high on the practical skill level of the rescue agency. Society also expects rescue organizations to provide a rapid response and effective work efforts in emergencies [9]. According to the Swedish National Board of Health and Welfare [10], "being ready" means being prepared for future developments and/or situations. Healthcare disaster preparedness includes all the work required for the care of affected persons, as well as minimizing the physical and psychological consequences of a major incident or disaster. In Sweden, each county council is responsible for coordinating EMS, including the disaster medical preparedness plan in time of peace, and for highlighting the plan for increased awareness.

Within the area described above scientific knowledge of EMS personnel preparedness is very limited. The purpose of this study is to survey the preparedness for major incidents in the mining industry among Swedish EMS personnel.

\section{Method}

This national study is a cross-sectional study, based on data collected by means of a study-specific questionnaire covering demographics, planning and preparedness of major incident in underground mines, if they have experienced a major incident and education and information. Both closed and open-ended questions were used.

Totally, there are nine underground mines in the Middle and North of Sweden. Employees from 13 EMS stations covering the mine areas participated in the study. Two hundred and fifty-eight persons were eligible and 137 (53\%) chose to participate in the study. The participants received information about the purpose of the study and its clinical relevance. They were also informed of voluntary participation. The findings are based on statistical analysis, i.e. using descriptive statistics and for differences among groups the Chi-Squared test, Continuity Correction and t-test were used.

\section{Results}

Participants ( $n=137)$ were on average 43 years old (21-64 years), both men (72\%) and women (37\%). They had worked on average 15 years (0-43 years), had various levels of education and work experience in the EMS. One third of the participants (36.5\%) had been trained by their respective employer (see Table 1). The training aimed at increasing preparedness for a major incident in an underground mine.

Half of the participants had a sense of not being prepared to work at a major incident in a mine. No significant differences were found concerning sex and educational level. It was a significant difference ( $p=$ 0.006) between those who had worked longer concerning their sense of being prepared for a major incident, which means they were more prepared. Those who had received training were significantly more prepared than those who had not $(p=$ 0.047, Table 2).

Those who had been down in a mine reported themselves to be more prepared for a major incident in the underground mine than others ( $p=0.017$, Table 3$)$. The 53 (39.6\%) participants who claimed to have worked at a major incident in the mining industry were not better prepared than those who lacked the experience ( $p=0.201$, Table 3 ).

Of the participants $19 \%$ knew of a disaster plan for major incidents at a mine at their present work. Further, the education received were mostly lectures and written information and to a smaller degree practical exercises in a mine. Almost all participants (91\%) reported they would benefit from some kind of training before a major incident in the mining industry happens. More practical exercises in a mine and lectures were the most desired educations among participants. 
Table 1 Demographic data by sex, education and, training received from employers $(n=137)$.

\begin{tabular}{ll}
\hline & $\mathrm{n}(\%)$ \\
\hline Sex & $37(27)$ \\
Females & $98(72.3)$ \\
Men & $60(43.8)$ \\
Educational level & $38(27.7)$ \\
Spec. R.N.* & $39(28.5)$ \\
R.N. & $50(36.5)$ \\
Nurse assistant & $86(62.8)$ \\
Received training from current employer & $71(51.8)$ \\
Yes & $66(48.2)$ \\
No & \\
Part of Sweden & \\
North & \\
\hline
\end{tabular}

* Spec. R.N. = all R.N.s with at least one year supplementary education, e.g. in ambulance care or anesthesia.

Table 2 Difference in sense of preparedness by sex, education and whether or not the participant received training from current employer $(n=137)$.

\begin{tabular}{|c|c|c|c|c|c|}
\hline Prepared & $\begin{array}{l}\text { Yes } \\
\text { n (\%) }\end{array}$ & $\begin{array}{l}\text { No } \\
\text { n (\%) }\end{array}$ & $\begin{array}{l}\text { Total } \\
\mathrm{n}\end{array}$ & $\begin{array}{l}\text { Missing } \\
\text { n (\%) }\end{array}$ & $p$-value \\
\hline \multicolumn{6}{|l|}{ Sex } \\
\hline Woman & $16(43.2)$ & $21(56.8)$ & 37 & $2(1.5)$ & $0.300 *$ \\
\hline Man & $54(55.1)$ & 44 (44.9) & 98 & & \\
\hline \multicolumn{6}{|l|}{ Educational level } \\
\hline R.N. & $17(44.7)$ & $21(55.3)$ & 38 & $1(0.7)$ & \multirow[t]{2}{*}{$0.301 * *$} \\
\hline Nurse assistant & $24(61.5)$ & 15 (38.5) & 39 & & \\
\hline \multicolumn{6}{|l|}{ Received training } \\
\hline Yes & $32(64)$ & $18(36)$ & 50 & $2(1.5)$ & $0.047^{*}$ \\
\hline No & $38(44.7)$ & 47 (55.3) & 85 & & \\
\hline
\end{tabular}

* Chi-Squared test with Continuity Correction.

** Chi-Squared test.

Table 3 Experience of being down in a mine and work during a major incident in a mine related to preparedness.

\begin{tabular}{|c|c|c|c|c|c|}
\hline Prepared & Yes & No & Total & $\begin{array}{l}\text { Missing } \\
\mathrm{n}(\%)\end{array}$ & $P$-value \\
\hline \multicolumn{6}{|c|}{ Been down in a mine } \\
\hline Yes & 46 (61.3) & 29 (21.3) & 75 (100) & $1(0.7)$ & $0.017^{*}$ \\
\hline No & 24 (39.3) & $37(60.7)$ & $61(100)$ & & \\
\hline \multicolumn{6}{|c|}{ Experience of a major } \\
\hline Yes & $32(60.4)$ & 21 (39.6) & $53(100)$ & $4(2.9)$ & $0.201^{*}$ \\
\hline No & $38(47.5)$ & $42(52.5)$ & $80(100)$ & & \\
\hline
\end{tabular}

* Chi-Squared test with Continuity Correction.

\section{Discussion}

The main results are that half of the participants said they did not feel prepared to work in a major incident in an underground mine. Only one third of the participants had been trained by their employer. Almost all participants would benefit from some kind of training. The training that most of the participants desired was practical training on site or at a mine.

Practical training is a strong factor for preparedness and it is stated [11] that the participants who had experience from real CBRNE events, experienced no significant higher readiness than those who performed a CBRNE exercise. A study on the correlation between the number of hours of training between paramedics and fire personnel practicing for major 
incidents and disasters and the perceived preparedness for these events showed that the level of perceived preparedness increased with the number of hours practiced [12]. Exercises and interactions between individuals, teams and organizations have a significant impact of the effectiveness of an emergency response [13]. It was found in another study that practical exercise compared to real events attained a more lasting knowledge of the performance of triage, which also enhances the idea of supplementing theoretical training with practical exercises. Practical exercises allow for feedback and the correction of errors in a safe learning environment, compared to actual events [11].

Our result showed that only one fifth knew of a disaster plan. There is a risk that disaster plans become a desktop product that does not reach the people who are supposed to use them in the field. Despite clear disaster plans, it is necessary to hold regular disaster exercises where those plans are implemented. Major incidents are rare and, therefore, there is a risk of loss of knowledge about EMS care between incidents [14]. This can be viewed in light of that realistic disaster exercises have proven effective for EMS personnel to become familiar with disaster plans and identify shortcomings in various areas such as leadership, communication, triage, patient flow, materials, resources and security [15].

There is a desire that the employer should make great effort to arrange many different drills for staff. However, research has also shown that emergency personnel can greatly benefit from rare but well-arranged mass casualty practice. It can be difficult to finance large, realistic emergency exercises. There is a call for effective strategies to improve and maintain disaster preparedness [16].

The present result showed a significant difference between those who had previously been in an underground mine and those who had not been in an underground mine concerning their preparedness. The participants with experience from being down in a mine reported they were more prepared for a major incident compared to those with no experience. It would therefore be useful for EMS to arrange visits to a mine within their respective catchment area. In larger events when resources are scare previous training is essential, but also in smaller events when those who arrive may not be trained to handle specific situations [17].

The study specific questionnaire for this cross-sectional study does not fit for any validity and reliability tests and there is no intention to use it in other studies. However, the acceptable response rate (53\%) and the low rate of missing values (2.5\%) increase the trustworthiness of the results even if they have to be taken with caution.

\section{Conclusions}

The majority of the participants requested specific training in a mine area in order to increase their preparedness. More studies will be necessary to explore how joint exercises involving EMS, rescue personnel and mining companies affect staff knowledge and preparedness. A high level of preparedness also promotes effective work at sites, as well as meeting the society's expectations of the EMS.

\section{References}

[1] Engström, G., Angrén, J., Björnstig, U., and Saveman B.-I. (2017). Mass-Casualty Incidents in the Underground Mining Industry: The Haddon's Matrix Applied on an Integrative Literature Review. Disaster Medicine and Public Health Preparedness, 1-9. doi: https://doi.org/10.1017/dmp.2017.31.

[2] Boniface, R., Museru, L., Munthali, V., and Lett, R. 2013. "Occupational Injuries and Fatalities in a Tanzanite Mine: Need to Improve Workers Safety in Tanzania.” The Pan African Medical Journal 16.

[3] Chimamise, C., Gombe, N. T., Tshimanga, M., Chadambuka, A., Shambira, G., and Chimusoro, A. 2013. "Factors Associated with Severe Occupational Injuries at Mining Company in Zimbabwe, 2010: A Cross-Sectional Study.” The Pan African Medical Journal 14.

[4] Elegant, S. 2007. "Where the Coal Is Stained with Blood?” Time 169: 32-4.

[5] Dhillon, B. S. 2010. Mine Safety: A Modern Approach, 
London Springer Science \& Business Media.

[6] Tunnicliff, N. 2010. “The President Comments.” Kai Tiaki Nursing New Zealand 16: 5.

[7] Kowalski-Trakfler, K. M., Alexander, D. W., Brnish, M. J., Mcwilliams, L. J., and Reissman, D, B. 2009. Underground Coal Mining Disasters and Fatalities-United States, 1900-2006. Morbidity and Mortality Weekly Report, 1379-83.

[8] Muzaffar, S., Cummings, K., Hobbs, G., Allison, P., and Kreiss, K. 2013. "Factors Associated with Fa-tal Mining Injuries among Contractors and Operators.” Journal of Emergency Medicine 55: 1337-44.

[9] Fattah, S., Kruger, A. J., Andersen, J. E., Vigerust, T., and Rehn, M. 2012. "Major Incident Preparedness and On-site Work among Norwegian Rescue Personnel-A Cross-Sectional Study." International Journal of Emergency Medicine 5: 1-7.

[10] The Swedish National Board of Health and Welfare. 2009. Socialstyrelsens föreskrifter (SOSFS 2009:10) om allmänna råd om Ambulanssjukvård mm. [General advice of prehospital emergency care etc.] Stockholm: Socialstyrelsen.

[11] Stevens, G., Jones, A., Smith, G., Nelson, J., Agho, K., Taylor, M., and Raphael, B. 2010. "Determinants of Paramedic Response Readiness for CBRNE Threats.” Biosecurity and Bioterrorism: Biodefense Strategy, Practice, and Science 8: 193-202.

[12] Fernandez, A. R., Studnek, J. R., Margolis, G. S., Mac, C.
J., Bentley, M. A., and Marcozzi, D. 2011. "Disaster Preparedness of Nationally Certified Emergency Medical Services Professionals.” Academic Emergency Medicine 18: 403-12.

[13] Stachowski, A. A., Kaplan, S. A., and Waller, M. J. 2009. "The Benefits of Flexible Team Interaction during Crises." Journal of Applied Psychology 94: 1536.

[14] Mahoney, E. J., Harrington, D. T., Biffl, W. L., Metzger, J., Oka, T., and Cioffi, W. G. 2005. "Lessons Learned from a Nightclub Fire: Institutional Disaster Preparedness." Journal of Trauma and Acute Care Surgery 58: 487-91.

[15] Hsu, E. B., Jenckes, M. W., Catlett, C. L., Robinson, K. A., Feuerstein, C., Cosgrove, S. E., Green, G. B., and Bass, E. B. 2004. "Effectiveness of Hospital Staff Mass-Casualty Incident Training Methods: A Systematic Literature Review.” Prehospital and Disaster Medicine 19: 191-9.

[16] Bartley, B. H., Stella, J. B., and Walsh, L. D. 2006. "What a Disaster?! Assessing Utility of Simulated Disaster Exercise and Educational Process for Improving Hospital Preparedness." Prehospital and Disaster Medicine 21: 249-55.

[17] Scholtens, A. 2008. "Controlled Collaboration in Disaster and Crisis Management in the Netherlands, History and Practice of an Overestimated and Underestimated Concept.” Journal of Contingencies and Crisis Management 16: 195-207. 